Preprint of:

Krupka, Douglas J. and Douglas S. Noonan. 2009. "Empowerment Zones, Neighborhood Change and Owner-Occupied Housing.” Regional Science and Urban Economics 39(4): 386-396.

Available at:

http://dx.doi.org/10.1016/j.regsciurbeco.2009.03.001

\title{
Empowerment Zones, Neighborhood Change and Owner-Occupied Housing.
}

\author{
Douglas J. Krupka (IZA, Bonn) \\ Douglas S. Noonan (Georgia Institute of Technology)
}

\begin{abstract}
This paper examines the effects of a generous, spatially-targeted economic development policy (the federal Empowerment Zone program) on local neighborhood characteristics and on the neighborhood quality of life, taking into account the interactions amongst the policy, changes in neighborhood demographics and neighborhood housing stock. Urban economic theory posits that housing prices in a small area should increase as quality of life increases, because people will be willing to pay more to live in the area, but these changes in prices and quality of life will also affect the demographics of the population through sorting and the housing stock through reinvestment. Using census block-group-level data, we examine how housing prices respond to the Empowerment Zone policy intervention. Changes in the other dimensions of neighborhood quality (demographics and housing stock characteristics) will also help determine the total - or full - effect on housing values of the policy intervention. This paper estimates these direct and full effects in a simultaneous equations setting, compares direct and indirect effects and examines the robustness of the effects to alternate estimation strategies. We find strong evidence for substantively large and highly significant direct price effects, while results suggest that the indirect effects are substantively small or even negative.
\end{abstract}

JEL classification: R0; R21; R31; R38; R58; O1; C33

The authors would like to thank Geoffrey Turnbull, Brett Baden, Dan McMillen and two anonymous referees for helpful input and John Winters for valuable research assistance. The paper also benefited from the discussion of participants in sessions at the annual APPAM meetings in 2006, the AREUEA annual meetings in 2008 and participants in the Lincoln Institute of Land Policy "Impact of Public Policy on Land Values” workshop. This research benefited from the support of the Lincoln Institute of Land Policy. This document contains demographic data from Geolytics, Inc, East Brunswick, NJ. 


\section{Introduction}

Spatially targeted economic development policy has been a popular tool for addressing the problem of entrenched concentrations of poverty in urban areas. Such spatially targeted programs usually consist of tax incentives and other off-the-books expenditures. Over the 1980's many states created such programs, generically referred to as enterprise zones, ${ }^{1}$ which provide economic incentives (usually through tax abatements) for companies that create jobs in depressed areas. While the popularity of such programs is irrefutable, the efficacy of spatially targeted development incentives is not well understood. Although early case-study research suggested that the programs were effective, more recent research has cast this early consensus into considerable doubt.

During the Clinton administration, the Federal Government created a similar program, called Empowerment Zones (EZs). Designated EZs received at least \$100 million in federal Social Service Block Grant funds to be administered by the states with considerable latitude. Businesses in EZs are also eligible for a variety of tax incentives outlined in IRS (2004). These incentives include an employment tax credit of up to $\$ 3,000$ per qualified employee, increases in the amount of equipment and property purchases that can be deducted immediately instead of over time through depreciation (the section 179 deduction), the ability to postpone declaration of capital gains on qualified assets and increased exclusion of gains from sales of small business stock. Governments are allowed to issue tax-exempt bonds for qualified expenditures in EZs. State and local governments were encouraged to supplement the federal program with their own tax incentives and expenditures. This program was continued during the early years of the Bush administration. At present, the EZ initiative covers over 700 census tracts with a combined population of over 3 million individuals in 31 communities (Greenbaum and Bondonio 2004). Although the generosity of the program has

\footnotetext{
${ }^{1}$ Terminology in this field is unfortunately problematic, because the state-level programs have various names. In this paper, we use the term enterprise zone to signify any of the various state programs and Empowerment Zone (or EZ) to refer to the more generous federal program. A federal program called enterprise communities also exists, but this program is more similar to the state programs than the federal Empowerment Zone program.
} 
varied over time, total incentives and grant expenditures are valued at over $\$ 5$ billion, according to the Department of Housing and Urban Development (HUD 2009). Despite the extent of the program, the literature on the effects of the EZ program is relatively undeveloped compared to the literature on state enterprise zone programs.

In this paper, we examine the effects of the federal program over a wide variety of neighborhood-level indicators. We focus on the total effect of the Empowerment Zone intervention on home values, which likely includes not only direct effects but also several types of indirect effects. This approach conceives of neighborhood outcomes as the result of a complicated interplay between economic, demographic and housing market forces. Recent researchers have had trouble finding significant direct effects of spatially targeted economic development programs. By identifying both the direct effects and the indirect effects, our approach offers EZ status its "best chance" to show some positive effect on neighborhood quality.

Our results show that for our preferred measure of neighborhood quality (housing values) EZ status appears to have had statistically significant and substantial positive effects. The effects of EZ status on other neighborhood characteristics are more mixed. The indirect effects vary somewhat depending on specification and estimation method, but are generally either small or negative.

The rest of the paper is organized as follows. Section II reviews the literature on state and federal spatially targeted economic development incentives. Section III lays out a conceptual foundation for our empirical section, discusses the empirical specification and describes the data. Section IV presents and discusses the results. Section V concludes.

\section{Literature}

Winnick (1966) lays out a very strong case against place-based policy. The primary justification for spatially targeted economic development programs lies in the persistence of concentrations of 
poverty, mainly in urban areas. Kain (1968) framed the problem in terms of the spatial mismatch hypothesis $(\mathrm{SMH})$, which posited that blacks were prevented from commuting or moving to the suburbs, where their labor was demanded, and that low-skill jobs were prevented from moving into the central city, where the low-skill black population lived. The spatial mismatch of low-skill labor supply and low-skill labor demand causes the location-constrained inner-city residents to experience adverse labor market outcomes. Since that seminal paper, spatially-targeted policies have become popular at many levels of government. While the SMH enjoyed several decades of empirical support, more recent work taking into account the endogeneity of residence choice has cast some doubt on the causal relationship between spatial mismatch and poor central city labor market outcomes. $^{2}$ Whether the SMH holds or not, it is widely accepted by policy-makers and spatially targeted economic incentives can be seen as an attempt to correct for the cost differentials that keep businesses from locating in the inner city.

Even in the absence of a causal effect of spatial mismatch, local jurisdictions may wish to spur development within their boundaries to increase tax receipts. It is not far fetched to believe that localized tax incentives could be beneficial for local jurisdictions, even if they had no effect on the indigenous population. Bartik (1991) reviewed the literature on the effects of local taxes on business activity and found that the elasticity of business activity with respect to local tax rates lay somewhere between -1 and -3 . If this is true, decreasing local taxes (even in a small section of the jurisdiction) could be revenue-enhancing for local governments. ${ }^{3}$ These large elasticities suggest

\footnotetext{
${ }^{2}$ Gurmu et al.(2008) uses panel data to control for individual-specific fixed effects, finding that access to employment has little effect on employment outcomes for their sample of Atlanta-area TANF recipients. Kling et al. (2004) use the random assignment of neighborhood achieved in the Moving To Opportunity experiments to look at the effects of job access and find that the experimental group (who were encouraged to move to low-poverty neighborhoods) did not have better labor market outcomes.

${ }^{3}$ These elasticity figures pertain to changes in business activity within a metropolitan area. Elasticities are of much smaller magnitude (between -0.1 and -0.6) when comparing changes in business activity across large areas. This implies that any tax advantages a jurisdiction might expect are coming primarily from other near-by jurisdictions, not through the attraction of business from other parts of the country. Of course, in the case of targeted incentives, the lower taxes may
} 
that the effects of local tax incentives may be large and that enterprise zones may be an effective policy tool from a local perspective.

Research examining the effects of spatially targeted incentives has concentrated on the various state programs. While many studies have found that enterprise zones have faired well in terms of employment, Boarnet (2001) points to the many methodological pitfalls inherent in straight comparisons of zones to non-zone areas. More rigorous evaluations of the state programs have not been lacking. An extensive review of this literature can be found in Peters and Fisher (2002). They find that while early econometric studies of the effects of state enterprise zones usually found positive results (e.g., Erickson and Friedman 1990, Papke 1993, Papke 1994), more recent results have been much less favorable. ${ }^{4}$ Peters and Fisher offer several possible explanations for this set of findings. They suggest that the tax incentives are not generous enough to overcome the substantial disadvantages associated with the targeted areas. They also suggest that the administration of zones, which often put conditions on the incentives that exist, may reduce their attractiveness. Bondonio and Greenbaum (2007) suggests that the insignificant net effects mask countervailing positive effects on new firms and negative effects on existing firms (who exit the zone), along with a number of other interesting results. Lynch and Zax (2008) look at establishment-level data, finding little effect for the state program in Colorado. They suggest that the benefits of the program likely fall on immobile factors like commercial real estate. Landers (2006) finds similar results for the Ohio state program.

The literature examining the effects of the federal Empowerment Zone program is much less developed, but growing. It is important to note that selection into the EZ program differed

be drawing businesses away from other parts of the same jurisdiction. Such possibilities complicate cost/benefit analysis of such programs. In this paper we focus only on the local effects of the program, not the measurement of the benefits.

${ }^{4}$ Boarnet and Bogart (1996), Greenbaum (1998) Greenbaum and Engberg (2000), Engberg and Greenbaum (1999), Bondonio and Engberg (2000) and Peters and Fisher's (2002) own analysis all point towards this conclusion. Elvery (2004) is another very careful analysis that finds insignificant results of enterprise zone status. 
substantially from selection into state programs. In selecting federal Empowerment Zones, HUD required an application process. Applicant zones were evaluated not only on the demographic and economic "needs" of the zones, but also the expected efficacy of the applicants planned use of program funds. Wallace $(2003,2004)$ examines this process, while Greenbaum and Bondonio (2004) examine how the process has changed over the three rounds of the program. Oakley and Tsao (2006, 2007a, b) use propensity score matching, as in much of the recent literature on the state programs, to examine the effect of Chicago's and some other Empowerment Zones on a variety of socio-economic neighborhood outcomes. While they find some localized effects (e.g. on poverty and related variables in the case of Chicago's zone), they characterize the effects as underwhelming. When pooling four zones (in Chicago, Baltimore, Detroit and New York City), the intervention had no significant effects on poverty, unemployment or average household income.

Although most of the studies mentioned above examine job creation or employment outcomes, our primary variable of interest will be the value of owner-occupied housing in a neighborhood. We will also be examining the effect of EZ status on employment outcomes of neighborhood residents, yet this more traditional variable takes a secondary position in that we examine only the direct effects of the program on employment. This focus makes sense because the Empowerment Zone program is supposed to improve neighborhoods along a variety of dimensions (McCarthy 1998), not just improve employment outcomes. As such, the general quality of life in a neighborhood should be improved by the program. If the program is successful in making a neighborhood more attractive, the price of housing should increase (Rosen 1974, Bartik and Smith 1987). Our empirical approach allows us to examine the effects of EZ status on many other variables of more traditional concern (employment outcomes, poverty, etc.), but housing values will remain our focus. 
Two recent studies that look at the Empowerment Zone program direct effects on a national level are Hanson (2008) and Busso and Kline (2008). Busso and Kline (2008) use propensity score matching techniques to assess the causal, direct effects on a variety of neighborhood characteristics. They find significant, robust and generally positive effects on neighborhood racial makeup, employment, educational attainment poverty and home values. Hanson (2008) uses an instrumental variables approach to address the endogeneity of zone designation. He finds evidence of endogeneity among his sample of zone and rejected zone applicants, but is not willing to take a strong position on the final direct effects. When controlling for endogeneity, he finds no statistically significant effect on employment, although he finds very large effects on property values in some specifications.

\section{Empirical model and data}

We expect that the EZ program's effects will be various. EZ program tax incentives might increase demand for commercial or residential land. Alternatively, EZ program monies might be used to improve neighborhood amenities (e.g. infrastructure, parks, crime prevention, beautification). If additional social services are made available for zone residents, this could also increase the demand for residential land in the zone. These program effects will increase property values within the zone. We term these price effects due to changes in local amenities as the "direct effects” of the program.

At the same time - and depending on its local implementation - the EZ program could cause the neighborhood's demographics and the housing stock to change. If EZ expenditures somehow lower crime, families with children may be attracted to the neighborhood. EZ expenditures and tax incentives may encourage the construction of certain types of housing, or the demolition of vacant housing. If these neighborhood demographic and housing stock characteristics are valued by 
homeowners, neighborhood housing prices will respond to these neighborhood composition effects of the EZ program. We term these price changes as the "first-order indirect effects" of the program.

The indirect effects do not end there, however. If EZ incentives and expenditures change demographics or the housing stock, then these changes might induce further changes in each other. Incentives encouraging single-family, detached housing might force out poorer renters, while expenditures luring in more affluent residents might encourage developers to produced detached housing for these hoped-for in-migrants. To the extent that the market values more affluent, suburban style neighborhoods, there will be further changes in prices. We call these price changes due to the interaction of demographic and housing stock characteristics the "second-order indirect effects” of the EZ program.

Finally, to the extent that neighborhood demographics and housing stock respond to the changes in housing prices themselves, there will be a second round of adjustments in housing characteristics and neighborhood demographics induced by the price changes themselves. These second-round adjustments will cause further changes to the price of housing, which in turn will induce a third round of adjustment and so on in a "multiplier” process. We term both the first- and second-order indirect effects as well as the extra "kick" provided by the multiplier process as a general "indirect effect." Thus, the "full effect" is the direct effect plus the indirect effect. Below, we lay out an empirical model that allows us to estimate both the direct and the various indirect effects in a simultaneous equations setting.

\section{A. Empirical model}

The empirical model used is similar to Noonan et al.'s (2007), where standard hedonic considerations are used to motivate a first-stage hedonic equation of the form:

$$
P_{i t}=\beta+\beta_{P} P_{i t-1}+\beta_{E Z} E Z_{i t}+\beta_{S} S_{i t}+\beta_{N} N_{i t}+\beta_{M} M_{i t}+\varepsilon_{1 i}+\varepsilon_{1 t}+\varepsilon_{1 i t}
$$


where $t$ indexes time, $i$ indexes neighborhoods, $P$ is the log of the median house value value, $S$ is a vector of structural characteristics of the neighborhood housing stock, $N$ is a set of neighborhood demographic characteristics, $M$ is a vector of municipal characteristics such as public services and taxes that may vary with time. The equation includes a time-specific error term as well as a neighborhood-specific component $\left(\varepsilon_{1 i}\right)$ which captures the effects of unmeasured neighborhood attributes which affect housing prices. Finally, the EZ variable allows the designation of a neighborhood as an Empowerment Zone to have an independent effect on neighborhood attractiveness. Such an effect is possible if EZ tax incentives increase access to employment in the area, or the federal funds are used to improve neighborhood quality, or lower taxes.

This is essentially a partial adjustment model in prices, where neighborhood housing prices adjust incompletely towards a neighborhood-specific, time-varying long run equilibrium over the course of a decade: $P_{i t}-P_{i t-1}=\left(1-\beta_{P}\right)\left(P_{i t}^{*}-P_{i t-1}\right)+\varepsilon_{i t}$, where the non-price terms in our equation control for $P^{*}$. While the lagged price term is not usually included in first-stage hedonics, we include it because we do not want to impose the assumption that prices adjust fully. This assumption might be especially problematic in the context of our data (described below) because our prices are neighborhood medians derived from the census long form, not sales data. The values which owners assess to their homes may be slower to adjust to neighborhood change than sales prices, so the partial adjustment process makes sense in this context.

A problem with the OLS approach to the hedonic equation in levels is that the unobserved neighborhood characteristics, $\varepsilon_{1 i}$, can be correlated with the other variables of interest. This may be especially important in the context of EZs, since EZ designation was not randomly distributed, but was targeted at distressed neighborhoods (Greenbaum and Bondonio 2004). To mitigate this problem, we estimate the model in first differences. By identifying the parameters from withinneighborhood changes in neighborhood characteristics, this strategy purges our parameter estimate 
of bias from the omission of time-invariant variables (Mendelsohn et al. 1992, Zabel 1999). Our primary equation of interest can be expressed as in equation (1),

$$
\dot{P}_{i t}=\beta_{t}+\beta_{P} \dot{P}_{i t-1}+\beta_{E Z} \dot{E} Z_{i t}+\beta_{S} \dot{S}_{i t}+\beta_{N} \dot{N}_{i t}+\beta_{M} \dot{M}_{i t}+\dot{\varepsilon}_{1 i t}
$$

where $\dot{X}_{i t}=X_{i, t}-X_{i, t-1}$ and $\beta_{t}=\varepsilon_{1 t}-\varepsilon_{1 t-1}$. Differenced out of this equation are the time-invariant factors affecting prices, $\varepsilon_{1 i}$. This differencing eliminates one possible source of endogeneity. In the regressions reported below, we actually allow several time-invariant variables to be included (interacted with time) and thus affect neighborhood price appreciation. These additions to the model are described in section III.C.

It is likely that many of the variables in equation (1) are set simultaneously with price, however, so that equation (1) is part of a larger system. If changes in neighborhood quality also affect the types of housing and demographic characteristics, it will be important to control for the simultaneity bias when estimating the direct and indirect effects of federal intervention on home values. As with housing prices, we model the neighborhood housing stock as a partial adjustment process, with current levels a function of lagged levels and other variables. Like equation (1), we run the regressions in first differences:

$$
\dot{S}_{i t}=\gamma_{t}+\gamma_{S} \dot{S}_{i t-1}+\gamma_{E Z} \dot{E} Z_{i t}+\gamma_{N} \dot{N}_{i t}+\gamma_{P} \dot{P}_{i t}+\gamma_{M} \dot{M}_{i t}+\dot{\varepsilon}_{2 i t}
$$

Here, the housing stock depends on its past levels, Empowerment Zone status, neighborhood demographics, price and other considerations. The kind of housing built in a neighborhood depends upon past levels because housing is a very durable asset and changes in the housing stock (at the aggregate level) will be gradual. These structural characteristics might also depend on EZ designation if program funds are used to clear abandoned housing or to subsidize construction of new housing. The housing stock may also depend on the neighborhood demographics (if rich people demand different kinds of housing than poor people), municipal-level variables (zoning restrictions, tax treatment) and geographic variables (which are differenced out of equation (2)). Finally, the 
price of housing may affect the kind of housing built because housing is produced using land and capital. Production theory suggests that if land becomes more expensive, some substitution towards capital will occur. Since our price variable includes the value of the land on which a unit sits, we expect some effect, although the sign depends on substitution elasticities in the production and consumption of housing services.

We apply similar logic to the modeling of neighborhood demographic characteristics. Neighborhood demographics follow a partial adjustment process and we difference the equation to control for unobserved fixed effects.

$$
\dot{N}_{i t}=\delta_{t}+\delta_{N} \dot{N}_{i t-1}+\delta_{E Z} \dot{E} Z_{i t}+\delta_{S} \dot{S}_{i t}+\delta_{P} \dot{P}_{i t}+\delta_{M} \dot{M}_{i t}+\dot{\varepsilon}_{3 i t}
$$

In equation (3), lagged changes in demographics are persistent because housing market frictions prevent neighborhood demographics from reaching their equilibrium levels between periods. Demographic groups’ differing demands for neighborhood quality or services provided by the EZ program may cause them to sort into neighborhoods being improved by EZ programs according to their willingness to pay for these attributes (Diamond and Tolley, 1982). Similar sorting according to municipal characteristics would be expected. Similarly, changes in housing stock may differentially attract different demographics, at least when the capital stock is somewhat inelastic. Finally, the price level in a neighborhood could affect neighborhood demographics if certain demographics are “priced out” of a neighborhood when prices increase.

The system of first-differenced equations (1)-(3) can be represented in matrix notation as in equation (4).

$$
\left[\begin{array}{ccc}
1 & -\beta_{S} & -\beta_{N} \\
-\gamma_{P} & 1 & -\gamma_{N} \\
-\delta_{P} & -\delta_{S} & 1
\end{array}\right]\left[\begin{array}{c}
\dot{P}_{i t} \\
\dot{S}_{i t} \\
\dot{N}_{i t}
\end{array}\right]=\left[\begin{array}{c}
\beta_{E Z} \\
\gamma_{E Z} \\
\delta_{E Z}
\end{array}\right] \dot{E}_{i t}+\left[\begin{array}{c}
\beta_{M} \\
\gamma_{M} \\
\delta_{M}
\end{array}\right] \dot{M}_{i t}+\left[\begin{array}{c}
\beta_{t}+\beta_{P} \dot{P}_{i t-1}+\dot{\varepsilon}_{1 i t} \\
\gamma_{t}+\gamma_{S} \dot{S}_{i t-1}+\dot{\varepsilon}_{2 i t} \\
\delta_{t}+\delta_{N} \dot{N}_{i t-1}+\dot{\varepsilon}_{3 i t}
\end{array}\right] .
$$


In this paper, we are specifically interested in the total effect of the EZ policy intervention.

System of equations (4) shows us that these effects depend on its direct effect ( $\left.\beta_{E Z}\right)$ and also on its indirect effects. Totally differentiating and dividing through by $d \dot{E} Z$ yields:

$$
\left[\begin{array}{ccc}
1 & -\beta_{S} & -\beta_{N} \\
-\gamma_{P} & 1 & -\gamma_{N} \\
-\delta_{P} & -\delta_{S} & 1
\end{array}\right]\left[\begin{array}{c}
d \dot{P} / d \dot{E} Z \\
d \dot{S} / d \dot{E} Z \\
d \dot{N} / d \dot{E} Z
\end{array}\right]=\left[\begin{array}{c}
\beta_{E Z} \\
\gamma_{E Z} \\
\delta_{E Z}
\end{array}\right] .
$$

The full effect on neighborhood housing prices due to the implementation of the Empowerment Zone policy is thus available through the application of Cramer's Rule:

$$
\frac{d \dot{P}}{d \dot{E} Z}=\frac{\beta_{E Z}+\beta_{S} \gamma_{E Z}+\beta_{N} \delta_{E Z}+\beta_{S} \gamma_{N} \delta_{E Z}+\beta_{N} \delta_{S} \gamma_{E Z}-\beta_{E Z} \gamma_{N} \delta_{S}}{1-\beta_{S}\left(\gamma_{N} \delta_{P}+\gamma_{P}\right)-\beta_{N}\left(\delta_{S} \gamma_{P}+\delta_{P}\right)-\gamma_{N} \delta_{S}}
$$

This expression for the full effect relates closely to the intuition laid out in our conceptual model at the beginning of this section. The "direct effect" on price is captured by the first term in the numerator. The next two terms are the "first-order indirect effects": $\dot{E} Z$ 's effect on $\dot{P}$ through $\dot{S}$ and $\dot{N}$. The fourth and fifth terms represent "second-order indirect effects": $\dot{E} Z$ 's effect on $\dot{P}$ through $\dot{S}$ 's effect on $\dot{N}$ and $\dot{N}$ 's effect on $\dot{S}$. The negative term corrects for double counting. The denominator accounts for the bidirectional effects of $\dot{P}$ on $\dot{S}$ and $\dot{N}$ and their effects back on $\dot{P}$, described as a "multiplier effect" above. If there is no simultaneity in equation (4) this total derivative reduces to the first three terms in the numerator.

As in Noonan et al. (2007), the system of equations is considerably more complex because $S$ and $N$ are vectors. We assume that each variable in $N$ depends on its own lag; the vectors $E Z, S$ and $M$; and the contemporaneous values of the other variables in $N$. Likewise, each $S$ variable is assumed to depend on its own lag; the vectors $E Z, N$ and $M$; and the contemporaneous values of the other variables in $S$. Our implementation of the system in equation (4) thus models each $\dot{S}$ and $\dot{N}$ 
equation as dependent on that variable's own lagged difference, $\dot{E} Z, \dot{M}$ and the other endogenous variables.

This paper tries to disentangle both the direct and indirect effects of EZ program participation. To this end, the system of equations represented in (4) is estimated simultaneously. To do so, we require at least one exogenous variable for each endogenous variable in each equation. The partial adjustment theory used to generate the empirical equations suggests the twice-lagged levels of each variable will be both exogenous and excludable in the context above. These excluded variables will be sufficient to just identify the system and allow estimation. ${ }^{5}$

There is a simpler method for estimating a full effect of the policy. In estimating equation (1) with OLS, the coefficient $\beta_{E Z}$ represents the partial or direct effect of the Empowerment Zone policy intervention on prices, holding other endogenous variables constant. However, if equation (1) were estimated constraining $\beta_{S}$ and $\beta_{N}$ to be zero (equivalently, omitting the endogenous variables from the regression), the returned coefficient on the policy variable $E Z$ will represent the effect of the policy intervention holding nothing constant. In other words, estimation of a price equation containing only the exogenous variables and EZ will return an unbiased estimate of the full effect computed in equation (6). The difference between the direct and full effects is what we call the “indirect effect." While this approach to the indirect effects makes it impossible to trace the avenues by which the indirect effects are generated (through $S$ or through $N$ ), it is simple and possibly more robust to misspecification than the systems approach. For that reason, in this paper we will compute indirect and full effects by both methods.

\footnotetext{
${ }^{5}$ Specifically, we have 18 endogenous variables ( $11 N$ variables, $6 S$ variables and $P$ ). Taking the price equation as an example, there are 18 endogenous variables in this equation (the 17 contemporaneous changes in the $N$ and $S$ variables and the lagged change in prices). As excluded instruments, we use the twice-lagged levels of each of the variables, which provides 18 exclusion restrictions in the price equation, which just identifies the equation. The other 17 equations in the system are identified in the same way.
} 


\section{B. Exogeneity of $E Z$}

Up to this point, we have assumed that the designation of a neighborhood for EZ status is exogenous conditional on the other observed variables. This is a dubious assumption. Greenbaum and Bondonio (2004) show that EZs are less populated; are poorer; have more minorities, unemployment and renters; and have depressed housing values. Wallace (2003, 2004) shows that conditional on applying to become an EZ - an area was more likely to be designated an EZ if it was closer to the urban center, had higher poverty or was in a state with less experience with enterprise zones or more experience applying for federal funds. Wallace (2004) also shows that the makeup of the area’s congressional delegation also matters.

This non-random selection of EZs has been an important problem for researchers studying their effects. In the context of state programs, Greenbaum and Engberg (2000) use propensity scores to select a comparable sample of zip codes for comparison of the effects of targeted incentives and compare the effects of actual zone selection versus zip code characteristics. They find that on average, enterprise zones became worse, relative to non-zones, over the 1980's, but that once you control for area characteristics, the effects of being in a zone were mostly insignificant. Elvery (2004) uses propensity score matching and, after considerable effort, is able to get the estimated effect of being in the Florida or California state enterprise zone programs back up to insignificant. (More naïve estimates suggested negative effects.) The possibility that program administrators are less likely to spend valuable resources on areas that are likely to have substantial rejuvenation in the absence of the program suggests that a naïve estimate of the EZ program's effects will produce downward biased effects if the special nature of the treatment group is ignored. In this analysis, we address this problem in three ways.

The first way that the problem is addressed is through the differencing outlined above. If unobserved area characteristics are causing housing prices to be lower, residents to be less 
employable and housing to be less well-maintained, the first-differencing of all the equations and the resultant focus on changes will get rid of these effects.

If EZ status is granted to areas where unobserved factors are causing a relative stagnation in a neighborhood, however, then even the first-difference coefficients will be biased down. If there is something about the EZ neighborhoods that is causing them to become worse, degrading the housing stock and impoverishing the residents (relative to other neighborhoods), then leaving this factor out will bias our results. In a study that is national in scope, it is impossible to directly control for all these factors. Our second tactic is to seek out a comparison group that could reasonably be assumed to share trends in most of these unobserved factors and compare the EZ group to this comparison group.

To this end, we use the timing of the EZ program to identify such a group. Neighborhoods were granted EZ status in three waves: Round 1 in 1994, Round 2 in 1998 and Round 3 in 2001. It is reasonable to assume that the neighborhoods that entered the EZ program in these three waves are similar in the unobservable qualities that may negatively impact property values, neighborhood demographics and the upkeep of the neighborhood housing stock. However, our data period ends in April 2000, when the 2000 census was conducted. It is unreasonable to expect that selection into the 2001 round of EZ designation would have any causal effect on 1990-2000 trends in housing values, neighborhood demographics or housing stock. ${ }^{6}$ Thus, we take the experiences of the Round 3 EZ neighborhoods as representing the counterfactual of what would have happened to the Round $1 \mathrm{EZ}$ neighborhoods had the policy intervention not occurred, conditional on observables and timeinvariant unobservables. Our empirical equations consider EZ as a vector of EZ1, EZ2 and EZever, which indicate participation in Round 1, Round 2, or any round of the EZ, respectively. The

\footnotetext{
${ }^{6}$ The legislation enabling the third round of Empowerment Zones did not pass the legislature until Dec. $21^{\text {st }}, 2000$. Workshops for interested applicant jurisdictions occurred in June, 2001. Selection occurred on the last day of 2001, with the designation becoming effective the next day. Given this timeline, it is unlikely that even expectation effects could have increased prices in early 2000 in Round 3 EZs.
} 
coefficient for EZ1 can thus be interpreted as deviations from the control group, or the "program effect” of EZ selection.

The validity of this approach rests on the equivalence of the "unobserved effect" for the Round 1 and Round 3 EZ neighborhoods. ${ }^{7}$ The approach is valid whether HUD administrators attempted to use the program to help especially distressed neighborhoods, or whether they attempted to pick neighborhoods that were likely to rebound on their own to make the program look successful. If the decision rule (concerning the unobserved factors) changed between 1994 and 2001, the approach will fail to control for policy endogeneity. Similarly, if designation as a zone tends to immediately follow recent unobservable neighborhood decay, the identification strategy will overstate the effect of the program. Obviously, this cannot be directly tested. Greenbaum and Bondonio (2004) compare the tracts selected in the three rounds and find that Round 3 and Round 1 census tracts are not significantly different in median income and in value of owner-occupied housing, although they differ in many other (observable) respects. ${ }^{8}$ They also show that the relationship between the probability of selection into an EZ and various observable characteristics differed between rounds and that in the later rounds selection appears to depend less on observable characteristics. $^{9}$

In our data, across the 17 neighborhood-level variables we examine, the difference in the changes experienced over the 1980's for Round 1 and Round 3 neighborhoods are statistically different from one another for nine (eleven) variables at the $0.05(0.1)$ significance level. While these differences are statistically significant, they are generally substantively small. The difference

\footnotetext{
${ }^{7}$ It bears emphasis that if unobserved factors in levels differ, they will be differenced out. Only difference in the changes in unobserved factors will affect our results.

${ }^{8}$ It should be stressed that while the statistical significance of these difference is often extreme, the substantive differences are less extreme except in the case of population density. Round 3 EZ neighborhoods still have relatively high unemployment, poverty and minority rates and low education, rental and ownership rates.

${ }^{9}$ This last result could be arising because the selection process was becoming more focused on the unobservables, or because the selection process was becoming more random.
} 
between Round 1 and Round 3 1980s changes is greater than half a standard deviation in only one case (population density) and is less than a tenth of a standard deviation for nine of the variables. In our empirical section, the control variables will take care of the variables that differ in observable ways between Round 1 and Round 3 EZs. We will have to hope that any remaining unobserved “distressed neighborhood” effect is time-invariant and washed away in the first-differencing or that the time-varying unobservable effect is the same for Round 1 and Round 3 EZs. That these assumptions are reasonable is supported by the fact that, controlling for metropolitan fixed effects, there is no significant difference between the appreciation rates of median home values over the 1980s between the two groups of block groups. The similarity in price movements during the 1980s is consistent with the assumptions that, absent the federal intervention, the experiences in the 1990s would also have been similar.

Out of an abundance of caution, we also explore another approach to the possible endogeneity of EZ designation. Because of our simultaneous equation setting, the propensity score methods used by Busso and Kline (2008) are not available to us. Instead, we take Hanson (2008) as inspiration in attempting to generate instrument for the designation of a neighborhood as an Empowerment Zone in the first round. In an auxiliary regression, we use a probit model to predict the first-round designation decision with information about the neighborhood's congressional delegation and other predetermined variables known to HUD at the time of designation. ${ }^{10}$ From this analysis, we generate the neighborhood-specific probability of designation, $\hat{E} Z$, and enter this fitted value into the system of equations described above in lieu of EZ. As will become apparent below,

\footnotetext{
${ }^{10}$ The regressors used in this auxiliary probit are predetermined or use data measured before 1994. This includes lagged differences (1980-1990) and twice-lagged levels (1980) in the $S$ and $N$ and $M$ vectors (see Table 1), with the exception of school district spending which was unavailable for 1980. The vector of congressional variables has zone-level measures of years of seniority of the most senior Senator; total seniority of senators; number of senators on Appropriations committee and the number of senators of the majority party on that committee; number of senators on Banking, Housing and Urban Affairs committee, number of majority party senators on that committee and number of senators chairing that committee; a count of representatives for that zone and a count of democrat representatives for that zone.
} 
the results based on this additional analysis do not lead us to worry about out preferred identification strategy.

C. Data

The hedonic approach generally uses cross-sectional data to predict housing prices. A national database of individual home prices would be required to analyze a national program such as Empowerment Zones in this way. Such a database is not available, so we are forced to use neighborhood averages as proxies for these individual values. Using aggregated data limits the inferences that can be made about micro-level effects. Nonetheless, some hedonic research has shown that estimates using aggregate data produce reasonably accurate results (Freeman 1979, Nelson 1979, O’Byrne et al. 1985). ${ }^{11}$ Noonan et al. (2007) also find generally plausible implicit prices in OLS estimations using similar aggregated data. Moreover, the median housing value in a neighborhood (and other demographic variables) is quite important from a policy perspective.

Estimates of the effects of the EZ program on neighborhood measures are informative in their own right, even if they cannot be strictly interpreted as hedonic prices. Viewed in an epidemiological light, the effects of average policy treatments on average outcomes are perhaps less than ideal but still interesting.

An advantage of our data is that these neighborhood averages can be observed over time. We use neighborhood aggregate data to estimate the system of equations described in part A. We use block-group level census data for the census years 1980, 1990 and 2000 from Geolytics ${ }^{\circledR}$, Inc., which processes the data into constant census 2000 geographies. The constant geographies allow us

\footnotetext{
${ }^{11}$ See Shultz and King (2001) for additional review of the use of aggregated Census data in hedonics. Greenstone and Gallagher (2008) use a similar data set for their analysis of superfund designation, although they use the larger geography of the census tract.
} 
to take the neighborhood (block group) as the unit of observation and observe developing neighborhood outcomes as time elapses.

There are four types of variables in the empirical model sketched in subsection A: $P, N, S$ and $M . P$ is measured with the log of the median housing value as reported in the census long form. The neighborhood composition variables, $N$, include the proportion of families with at least one worker, the proportion of households with incomes at or below 150 percent of the poverty line, the log of median household income, the proportion of people reported as being white and non-Hispanic, the average commute time for workers, the population density, the proportion employed in manufacturing industries, the proportion of households who rent their property, the proportion of the population that lived in the same home five years prior to the census, the proportion of households that have children and the proportion of the population aged over 25 with a college degree. These variables were chosen either because they have been shown in hedonic studies to affect housing values (e.g., population density, percent white), or because they are variables of special interest in the local economic development literature (e.g., percent working families). All these variables are measured as changes from 1990 to 2000.

The housing stock variables, $S$, include the vacancy rate of neighborhood housing units; the median year built; the proportion of neighborhood housing units that are in buildings with four or fewer units; the average number of rooms; the average number of bedrooms and the percent of the housing stock built within the previous decade. ${ }^{12}$ These are most of the relevant variables included in the census long form. With the exception of new construction, all these variables are measured as changes from 1990 to 2000.

\footnotetext{
${ }^{12}$ The proportion of housing units constructed since the last census enters the $\dot{S}$ vector directly, capturing the flow of housing construction activity in the block group in ways that perhaps median year built does not. Roughly speaking, the new construction variable is the number of housing units, first-differenced as with all other variables and scaled so it is a proportion variable.
} 
The variables discussed thus far are all endogenous: they are part of the system of equations. We also include several exogenous variables. The municipal-level variables, $M$, include measures derived from the census defined place containing the neighborhood. ${ }^{13}$ These measures include the place population, median income, housing value and rental rate (all logged), the proportion of families that have children and families that are "traditional families" with children. These variables are meant to capture the municipality's tax base (income, housing values, rents and household count) and service provisions (the family variables). We also include a variable derived from the National Center for Education Statistics (NCES) School District Demographic System (SDDS) and the 1992 and 2002 Census of Governments measuring per pupil expenditure in the elementary or unified school district that contains the centroid of the block group as a measure of public service quality. These variables are measured as changes from 1990 to $2000 .{ }^{14}$ MSA fixed effects are included in all the results reported below. In the $P$ equation we also include a county-level natural amenity score (USDA 1999) and the interaction of the MSA fixed effect with the distance to the nearest historical city center. ${ }^{15}$ As time-invariant geographic attributes, these variables enter the structural model interacted with time, thus relaxing the assumption of constant hedonic prices over time for these characteristics. Importantly, the addition of MSA fixed effects allows metropolitan areas to have idiosyncratic average appreciation rates, and we identify all our effects off intra-metropolitan variation.

Finally, our variable of interest, EZ, includes three dummy variables. These variables indicate when, if ever, the block group was included in the EZ program. (Block-groups could be

\footnotetext{
${ }^{13}$ The place is the census's closest approximation of the municipal or jurisdictional geography. For areas falling outside any place, the county-level values are used, since such areas will presumably get their services from a county government instead of a municipal government.

${ }^{14}$ These place-level variables are considered exogenous on the logic that any one block group will make up a smallenough proportion of the place that it has negligible effect on place-level averages.

${ }^{15}$ The exclusion of these exogenous factors from the non-price equations supplies us with hundreds of additional exclusion restrictions raising the risk of overidentification.
} 
selected at most once in Rounds 1, 2, or 3.) EZ comprises two dummy variables (EZ1 and EZ2), equaling one if the block group fell into the first or second round and a third dummy variable (EZever) that equals one if the block group was ever in an EZ, including the post-2000 census Round 3. EZ1 and EZ2 can be interpreted as changes in EZ status over the course of the 1990's, while the variable EZever is merely a control variable, as discussed above. The interpretations of the coefficients on EZ1 and EZ2 is thus the effect these variables have on the dependent variables, controlling for the fact that they have the unobserved "distressed” characteristic, as represented by the EZever variable.

Table 1 presents the average changes for all the variables for which we report results. This table presents averages for the full sample of metropolitan block groups and the sub-sample average changes for block groups in each round of EZs. It is worth noting the strong appreciation of Round 1 Empowerment Zones and the weak appreciation of Round 3 Empowerment Zones; Round 1 zones appreciated over 35\% faster in the 1990s. This is a pattern that is preserved in the regression results reported below.

\section{Results}

Table 2 presents our OLS estimates of the direct and full effects of EZ designation. Besides the variables reported in these tables, we are controlling for metropolitan fixed effects (by measuring all variables as differences from metropolitan averages) as well as city-specific "rent gradients” and county-level natural amenity scores. In column 2.1, we see the that controlling for metropolitan fixed effects, some time-invariant geographical factors, place-level variables and neighborhood-level controls reduces the effect of EZ Round 1 designation relative to the conditional means presented in Table 1, but the effects are still quite large. The coefficient of about 0.22 implies that median home value appreciation was about 25\% faster in Round 1 neighborhoods relative to what would have 
occurred without the program. None of the control variables are particularly surprising in their sign. Column 2.2 reports results when the endogenous variables are dropped. By not holding these variables constant, we allow the indirect effects of EZ designation that might have worked through these neighborhood characteristics to be included in the coefficient of EZ Round 1. However, the effect on the coefficient is tiny; the coefficients are identical through the fourth significant digit! This suggests that the indirect effects are small or offsetting.

The large program effect could be explained by endogenous choice of Round 1 zones. Columns 2.3 and 2.4 report results from OLS regressions run with the predicted probability of Round 1 designation in the place of the vector of program controls used for identification in the first two columns. While the standard errors of these coefficients are biased downward, it is not likely to affect the outcome of any hypothesis tests: the coefficients using this two-step procedure are much larger than those using the Round 3 zones as a control group and the qualitative difference between the direct and full effects are similar whichever identification strategy is used. These results increase our confidence in our preferred identification strategy that - if anything - appears to be conservative. It bears emphasis that these price effects are in line with the most current research on the federal EZ program, presented in Busso and Kline (2008) and Hanson (2008), both of which report substantial property value effects.

There are at least four reasons why the program effects in Table 2 appear so much larger than those in Greenbaum and Engberg (2000) and other appraisals of state enterprise zone programs. First, and most obviously, the EZ program differed from most state programs in that it offered not only tax incentives but substantial grants. The influx of federal dollars and the services and community improvements that can be achieved with that spending may have a larger effect on land values (or other variables) than tax incentives alone. Second, the fact that the EZ program is federal and included federal tax incentives (usually on top of state and local incentives) probably means that 
the tax incentives were stronger than in state enterprise zones. Also, the federal EZ program may have gotten better publicity in local media, helping businesses become aware of the potential benefits. Finally, there are measurement issues that suggest the difference between these results and previous results may be (slightly) over-stated. Most previous studies have been forced to use zip codes for information on employment, or other neighborhood outcomes. Zip code boundaries do not match well with state enterprise zone boundaries. Even if a study uses census tract or block group data, state enterprise zones were not drawn according to census geographies. Researchers are forced to assign zone status to partially designated zip codes (or census tracts) according to some decision rule. However justifiable that decision rule is, it will mean that the independent variable "enterprise zone” is measured with error, biasing the coefficient towards zero. With the federal Empowerment Zone program, zone boundaries were drawn to match very closely to 1990 census geographies. Thus, the measure of program status we are able to obtain for the federal program is relatively error free. This eliminates a downward bias that is present in most state enterprise zone studies.

Table 3 presents the results of the three-stage least-squares estimation described above. Column 3.1 presents the results when identifying EZ program effects with the comparison group of EZ Round 3 neighborhoods. Column 3.2 reports the results using the auxiliary regression to identify the effects. Within each column, there are two sub-columns. In the first, the coefficients from the price equation are reported. In the second, the coefficient on the EZ Round 1 variable in each of the other second-stage equations is reported. Referring back to equation (4), the first columns report all of the $\beta$ coefficients, while the second columns present the $\gamma_{E Z}$ and $\delta_{E Z}$ coefficients from the nonprice equations that are estimated simultaneously in the same model. The other $\gamma$ and $\delta$ coefficients are too numerous to present here, but they are available from the authors upon request.

Table 3 shows that controlling for the various simultaneous relationships between the endogenous variables increases the point estimates of the EZ program effect to about $40 \%$. In 
column 3.2 we see the estimated effect is even higher at over $60 \%$ when identified using the auxiliary regression. The coefficient on EZ ever suggests that had the Round 1 zone neighborhoods not been in the program, median property values would have fallen by almost $20 \%$ instead of increasing by about $20 \%$.

The two identification strategies are in substantial agreement on the EZ program's effects on non-price neighborhood characteristics as well. For eight variables, the identification strategies yield qualitatively similar results (although the effect sizes tend to be much larger in column 3.2). These effects included increases in the percentage of families with working adults, the poverty rate, the percent white, the percent of households with at least one child and the percent of new construction in the neighborhood. They also include decreases in population density, the median year built and the average number of rooms in occupied housing units. Of the seven variables with insignificant program effects in one of the specifications, the point estimates are at least of the same sign for five of them (positive for median income, average commute, vacancy rate and proportion long term residents; negative for percent of workers employed in industry). Only two variables have significant estimated program effects of opposite sign across the two specifications (proportion with college degrees and average number of bedrooms). We would characterize these effects as mixed, based on our understanding of the goals of the policy. Whether these non-price effects are beneficial on net depends on how the effected characteristics are valued in the housing market.

The coefficients of the other endogenous variables in the price equation bear some discussion. First, many of the coefficients are large in the 3SLS models. The scale of the independent variables must be kept in mind when interpreting the size of the coefficients. The coefficient of over 4 for the proportion of small housing structures may sound large, but this means that a one percentage point increase in the proportion is associated with a 4 percent increase in median housing values. Perhaps only for the average rooms variables and the population density 
variable are the coefficients suspiciously large. Across the two models in Table 3, there is substantial agreement about the sign and rough magnitude of the effects. While some of these effects (and their changes from the OLS specification) are interesting in their own right, we note that, with a few exceptions, they match intuition well.

In Table 4, we add a control for areas bordering the EZ neighborhoods. There are two reasons to do this. First, observing the spill-over effects is interesting in its own right. Whether spatially targeted programs also benefit nearby areas (or impose costs on them) is an important dimension of evaluating the effects of such programs. Second, the inclusion of these affected areas in the control groups could potentially bias our estimates of the program effects. Table 4 reports the endogenous and program variables for models including half-mile buffers around the zone neighborhoods for each round. ${ }^{16}$ We see that estimated spill-over effects of the program on residential housing prices is positive and that the inclusion of these controls does not substantially change the estimated program effects within the round one empowerment zones in either the OLS model (column 4.1) or the 2SLS specification (column 4.2).

With these results in hand - and the empirical model laid out in Section III.A - it is possible to calculate the full effects of Empowerment Zone status in two ways. First, with the OLS models we can compare the ceteris paribus or “direct” program effect reported in columns 2.1, 2.3 and 4.1 with the mutatis mutandis or "full" program effects reported in columns 2.2 and 2.4 and to a parallel specification with buffers which was not reported. Second, by plugging the coefficients from the price equation and the other equations into an expanded equation (6), we can calculate the full effect and compare it to the direct effect for each of the 3 estimates of the system presented in equation (4). The results of these exercises are reported in Table 5, which reports the direct and full effects. The

\footnotetext{
${ }^{16}$ These control variables are measured as the percent of the block group that is within one half mile of an Empowerment Zone in the different rounds.
} 
indirect effect is computed from the difference of these effects. A final column compares the indirect effect to the standard error of the direct effect. While this last column is not appropriate for hypothesis testing, it gives some sense of our computed indirect effects in light of our uncertainty about the parameter estimates and it is available for all six of our models. The results are fairly consistent across models; indirect effects are insignificant in the OLS models and negative in the 2SLS models. In the case of the simultaneous equations estimation with spill-over effects, the indirect effect is quite large in magnitude, suggesting that the program effects substantially crowd themselves out. We find these results striking in light of the goals and rationale of the policy. Empowerment Zones were not billed as property value enhancement programs. Instead, they were understood as attempts to affect neighborhoods for the better across a number of dimensions. One would thus expect that the direct effects of Empowerment Zone interventions would be minimal, but that the indirect effects would be large. To the extent that the results in Table 5 tell a story, it is the exact opposite one. Across all models, the direct effects are very large. On the other hand, the indirect effects are either quite small by comparison (estimated in OLS), or actually negative (estimated in the systems of equations). The consistency of this story is striking; there are no results pointing towards large positive indirect effects.

\section{Conclusions}

This paper has examined the effects of a very generous economic development policy: the federal Empowerment Zone program. This program offers the best chance to find positive effects of spatially targeted economic development policies because on top of the state and local tax incentives, federal tax incentives and direct federal investment is added.

This paper contributes to the literature because it is one of the first attempts to explicitly account for the complex, interacting processes which generate neighborhood measures like home 
values, demographic characteristics and housing stock characteristics. While the equations we estimate are admittedly reduced form, the system of equations approach allows for a much richer picture of neighborhood outcomes to emerge.

Although studies of state enterprise zones have struggled to find significant effects, we find a sizeable and significant positive effect on home values and varying effects on other outcomes of interest. The significance and size of these effects are probably explained by the generosity of the federal program, along with better measurement of program status because of the close matching of EZ boundaries with census geographies. The indirect effects of EZ status on home prices through the other endogenous variables appear to be either extremely small or actually perverse. These results fit well into the existing literature on spatially targeted economic development programs. The recent literature on state programs (e.g. Bondonio and Greenbaum 2007), which rely completely on tax incentives, has shown them on net to be ineffective. Moreover, the developing literature on the effects of the federal program (Oakley and Tsao 2006, 2007a, b) finds generally unimpressive effects of the intervention on neighborhood indicators other than price. The results in this paper suggest that the federal grants are able to affect local quality of life with complex and not generally positive net effects on other neighborhood attributes.

We believe that these results raise questions about what the federal Empowerment Zone program has accomplished and how. The strong positive direct effect suggests the program is working, perhaps through improved amenities (better services, lower crime, better infrastructure or better access to employment). Another possibility is that the positive increase in price represents a composition effect. Density decreases in these neighborhoods. A possible interpretation is that federal money is being spent to knock down low-value homes, increasing the median value in a neighborhood. Such an intervention would provide little beneficial neighborhood revitalization and so we see the non-price effects of the program are extremely mixed. While this is possible, the sheer 
size of the EZ1 effect makes it unlikely that this is the only explanation. Some recent work by Lynch and Zax (2008) on the state program in Colorado suggests that some of the increased real estate prices could come through increased demand for commercial real estate (in order to gain access to program benefits) driving up the price of residential property. This interpretation is also adopted by Landers (2006) for Ohio’s state program and Hanson (2008) in the context of the federal program. We find the positive spill-over effects and the scattered beneficial non-price effects of the program to be evidence suggestive that something more than simple capitalization of benefits to business has transpired in these neighborhoods, although these effects certainly do not preclude this interpretation.

Another aspect worth examining is program heterogeneity. While this paper has concentrated on the average effect of the policy intervention, Oakley and Tsao (2006) show that there is some heterogeneity across Empowerment Zones in terms of the non-price effects of the program. This is to be expected since the actual policy intervention in each zone would differ according to the zone's administration, goals and strategies. Whether differences in policy outcomes are correlated with differences in the policy implementation in a sensible way is an interesting question. The identification strategy used here would not be appropriate for such an examination. Further work might also be done on the indirect effects of EZ status on the other variables. Two variables of interest are the family labor market variable and the poverty rate. Both are targets of the program and have been hypothesized to have positive externality effects in neighborhoods. The Empowerment Zone program seemed to have conflicting effects on these variables (increasing working families and poverty simultaneously). However, several other variables affected by the EZ program also affected labor market success and poverty outcomes, so the full effects might differ markedly from the direct effects of the program and may be more consistent across neighborhood characteristics. 
Spatially-targeted economic development programs are an important feature in the landscape of social policy in America. Because much of the cost of these programs is off the books, they are popular. The suite of policies at local, state and federal levels create considerable variation in the intensiveness of these interventions. Considerable effort has been and will continue to be directed towards understanding the effects of these policies and what works. To that end, this paper can be seen as adding to the literature in examining the effects of a very generous program. At the same time, these policy-induced variations in taxes and expenditures represent an opportunity to examine the forces affecting neighborhood change along a host of measurable dimensions. From that perspective, the differences in results across programs (state, federal) and across dimensions (price, non-price) offer insight into neighborhood dynamics and the workings of the various housing submarkets in metropolitan areas.

\section{References}

Bartik, Timothy J. (1991). "Who Benefits from State and Local Economic Development Policies?” Kalamazoo, MI: Upjohn Institute.

Bartik, Timothy J. and V. Kerry Smith (1987). “Urban Amenities and Public Policy.” In Mills, Edwin S., ed., Handbook of Regional and Urban Economics. Volume 2: Urban Economics. Amsterdam: Elsevier, pp. 1207-1254.

Boarnet, Marlon G. (2001). “Enterprise Zones and Job Creation: Linking Evaluation and Practice.” Economic Development Quarterly 15(3): 245-254.

Boarnet, Marlon G. and William Bogart (1996). "Enterprise Zones and Employment: Evidence from New Jersey.” Journal of Urban Economics 40(2): 198-215.

Bondonio, Daniele and John B. Engberg (2000). "Enterprise Zones and Local Employment: Evidence from the States’ Programs.” Regional Science and Urban Economics 30(5): 519-549.

Bondonio, Daniele and Robert T. Greenbaum (2007). "Do local tax incentives affect economic growth? What mean impacts miss in the analysis of enterprise zones policies.” Regional Science and Urban Economics 37(1): 121-136.

Busso, Matias and Patrick Kline (2008). "Do Local Economic Development Programs Work? Evidence from the Federal Empowerment Zone Program.” Cowles Foundation Discussion Paper 
No. 1638; Yale Economics Department Working Paper No. 36. Available at SSRN: http://ssrn.com/abstract $=1090838$

Diamond, Douglas B. Jr. and George S. Tolley (1982). “The Economic Roles of Urban Amenities,” in Diamond, Douglas B Jr. and George S. Tolley, eds., The Economics of Urban Amenities. New York: Academic Press. pp. 3-54.

Elvery, Joel A. (2009). “The Impact of Enterprise Zones on Resident Employment: An Evaluation of the Enterprise Zone Programs of California and Florida.” Economic Development Quarterly 23(1): 44-59.

Engberg, John B. and Robert T. Greenbaum (1999). "State Enterprise Zones and Housing Markets.” Journal of Housing Research 10(2): 163-187.

Erickson, Rodney and Susan Friedman (1990). "Enterprise Zones 2: A Comparative Analysis of Zone Performance and State Government Policies.” Environment and Planning C: Government and Policy 8(4): 363-378.

Freeman, A. Myrick III (1979). “The Hedonic Price Approach to Measuring Demand for Neighborhood Characteristics.” In Segal, David, ed. The Economics of Neighborhood. New York, Academic Press. pp. 191-217.

Greenbaum, Robert T. (1998). An Evaluation of State Enterprise Zone Policies: Measuring the Impact on Business Decisions and Housing Market Outcomes. unpublished PhD. Thesis, $\mathrm{H}$. John Heinz III School of Public Policy and Management. Pittsburgh: Carnegie Mellon University.

Greenbaum, Robert T. and Daniele Bondonio (2004). "Losing Focus: A Comparative Evaluation of Spatially Targeted Economic Revitalization Programmes in the US and the EU.” Regional Studies 38(3): 319-334.

Greenbaum, Robert T. and John B. Engberg (2000). “An Evaluation of State Enterprise Zone Policies.” Policy Studies Review 17(2/3): 29-46.

Greenstone, Michael and Justin Gallagher (2008). "Does Hazardous Waste Matter: Evidence from the Housing Market and the Superfund Program.” The Quarterly Journal of Economics 123(3): 951-1003.

Gurmu, Shiferaw, Keith R. Ihalnfeldt and William J. Smith (2008). “Does Residential Location Matter to the Employment of TANF Recipients? Evidence from a Dynamic Discrete Choice Model with Unobserved Effects.” Journal of Urban Economics 63(1): 325-351.

Hanson, Andrew (2008) "Poverty Reduction and Local Employment Effects of GeographicallyTargeted Tax Incentives and Grants: An Instrumental Variables Approach.” Urban and Regional Analysis Group Working Paper No. 08-10, Georgia State University, Andrew Young School of Policy Studies. 
HUD (2009). "Welcome to the Community Renewal Initiative.” http://www.hud.gov/offices/cpd/economicdevelopment/programs/rc/index.cfm , accessed on 3 March 2009.

Internal Revenue Service (2004). “Tax Incentives for Distressed Communities.” Publication number 954, catalogue number 20086A.

Kain, John (1968). "Housing Segregation, Negro Employment and Metropolitan Decentralization.” Quarterly Journal of Economics 82: 175-197.

Kling, Jeffrey R., Jeffrey B. Leibman, Lawrence F. Katz and Lisa Sanbonmatsu (2004). "Moving to Opportunity and Tranquility: Neighborhood Effects on Adult Economic Self-sufficiency and Health from a Randomized Housing Voucher Experiment.” Working paper no. 481, Industrial Relations Section, Princeton University. Available at: http://www.irs.princeton.edu/pubs/pdfs/481.pdf

Landers, Jim (2006). "Why don’t Enterprise Zones Work? Estimate of the Extent that EZ Benefits are Capitalized into Property Values.” Journal of Regional Analysis \& Policy 36(1): 15-30.

Lynch, Devon and Jeffrey S. Zax (2008). "Incidence and substitution in Enterprise Zone Programs: The case of Colorado” Unpublished working paper available at: http://www.colorado.edu/Economics/Zax/workingpapers/LynchandZax.pdf .

McCarthy, John (1998). “US Urban Empowerment Zones.” Land Use Policy 15(4): 319-330.

Mendelsohn, Robert, Daniel Hellerstein, Michael Huguenin, Robert Unsworth and Richard Brazee (1992). "Measuring Hazardous Waste Damages with Panel Models." Journal of Environmental Economics and Management 22: 259-271.

Nelson, Jon P. (1979) “Airport Noise, Location Rent, and the Market for Residential Amenities," Journal of Environmental Economics and Management, 6: 320-331.

Noonan, Douglas S., Douglas J. Krupka and Brett M.Baden (2007). “Neighborhood Dynamics and Price Effects of Superfund Site Clean-up.” Journal of Regional Science 47(4): 665-692.

Oakley, Deirdre and Hui-shien Tsao (2006). “A new way of revitalizing distressed urban communities? Assessing the impact of the federal empowerment zone program." Journal of Urban Affairs 25(5): 443-471.

Oakley, Deirdre and Hui-shien Tsao (2007a). "Socioeconomic gains and spillover effects of geographically targeted initiatives to combat distress: An examination of Chicago's Empowerment Zone.” Cities 24(1):43-59.

Oakley, Deirdre and Hui-shien Tsao (2007b). “The Bottom-Up Mandate: Fostering Community Partnerships and Combating Economic Distress in Chicago's Empowerment Zone.” Urban Studies 44(4): 819-843. 
O’Byrne, Patricia Habuda, Jon P. Nelson and Joseph J. Seneca (1985). “Housing Values, Census Estimates, and the Environmental Cost of Airport Noise: A Case Study of Atlanta.” Journal of Environmental Economics and Management 12(2): 169-178.

Papke, Leslie (1993). “What Do We Know about Enterprise Zones.” In Poterba, James, ed. Tax Policy and the Economy. Cambridge: National Bureau of Economic Research and MIT Press, pp. 37-72.

Papke, Leslie (1994). “Tax Policy and Urban Development: Evidence from the Indiana Enterprise Zone Program.” Journal of Public Economics 54(1): 37-49.

Peters, Alan H. and Peter S. Fisher (2002). “State Enterprise Zone Programs: Have they Worked?” Kalamazoo, MI: Upjohn Institute.

Rosen, Sherwin (1974). "Hedonic Prices and Implicit Markets: Product Differentiation in Pure Competition.” Journal of Political Economy 82(1): 34-55.

Shultz, Steven D. and David A. King (2001). “The Use of Census Data for Hedonic Price Estimates of Open-Space Amenities and Land Use.” Journal of Real Estate Finance and Economics 22(2/3): 239-252.

USDA ERS (1999) Natural Amenities Scale data file. Last accessed online 10 August 2005 at: http://www.ers.usda.gov/Data/NaturalAmenities/

Wallace, Marc A. (2003). “An Analysis of Presidential Preference in the Distribution of Empowerment Zones and Enterprise Communities.” Public Administration Review 63(5): 562572.

Wallace, Marc A. (2004). "Conressional Considerations and Urban Characteristics in the Selection of Empowerment Zones and Enterprise Communities.” Journal of Urban Affairs 26(5): 593609.

Winnick, L. (1966). "Place Prosperity vs. People Prosperity: Welfare Considerations in the Geographic Redistribution of Economic Activity,” in Real Estate Research Program, University of California at Los Angeles, Essays in Honor of the Sixty-fifth Birthday of Leo Grebler. Los Angeles, CA: Real Estate Research Program, pp. 273-283.

Zabel, Jeffrey E. (1999). “Controlling for Quality in Price Indices.” Journal of Real Estate Finance and Economics 19(3): 223-241. 
Table 1: Descriptive statistics for 1990's changes, main variables.

\begin{tabular}{|c|c|c|c|c|c|}
\hline & & \multicolumn{4}{|c|}{ Sample } \\
\hline & & All Metro & Round 1 & Round 2 & Round 3 \\
\hline \multirow{3}{*}{$E Z$} & Round 1 EZ & 0.0084 & $960^{\mathrm{a}}$ & 0 & 0 \\
\hline & Round 2 EZ & 0.0086 & 0 & $987^{\mathrm{a}}$ & 0 \\
\hline & Round 3 EZ & 0.0057 & 0 & 0 & $656^{\mathrm{a}}$ \\
\hline \multirow{2}{*}{$\boldsymbol{P}$} & log median home value & 0.3900 & 0.6278 & 0.3967 & 0.2672 \\
\hline & & 0.3210 & 0.5934 & 0.4019 & 0.3538 \\
\hline \multirow{22}{*}{$N$} & prop. working families & 0.0046 & 0.0865 & 0.0352 & 0.0390 \\
\hline & & 0.0957 & 0.1741 & 0.1489 & 0.1467 \\
\hline & $150 \%$ poverty rate & 0.0006 & -0.0377 & -0.0230 & -0.0307 \\
\hline & & 0.1058 & 0.1909 & 0.1395 & 0.1713 \\
\hline & log median income & 0.3342 & 0.4513 & 0.3534 & 0.4041 \\
\hline & & 0.2497 & 0.4717 & 0.3175 & 0.3952 \\
\hline & proportion White & -0.0817 & -0.0274 & -0.0584 & -0.0582 \\
\hline & & 0.1202 & 0.1162 & 0.1165 & 0.1357 \\
\hline & Avg. Commute (minutes) & 1.7811 & 1.8433 & 1.9511 & 1.6789 \\
\hline & & 4.9916 & 10.5922 & 7.0959 & 6.6937 \\
\hline & Population Density & 280.47 & -512.52 & -580.46 & -136.75 \\
\hline & & 2372.7 & 4527.1 & 8146.8 & 1990.9 \\
\hline & prop. Industrial employment & -0.0624 & -0.0776 & -0.0612 & -0.0465 \\
\hline & & 0.0893 & 0.1661 & 0.1092 & 0.1177 \\
\hline & prop. Renters & -0.0068 & -0.0244 & -0.0091 & 0.0092 \\
\hline & & 0.1087 & 0.1528 & 0.1119 & 0.1441 \\
\hline & prop. 5-yr resident & 0.0240 & 0.0117 & -0.0039 & 0.0089 \\
\hline & & 0.1334 & 0.1764 & 0.1360 & 0.1522 \\
\hline & prop. w/children & -0.0013 & 0.0054 & -0.0021 & -0.0047 \\
\hline & & 0.0666 & 0.1023 & 0.0816 & 0.0958 \\
\hline & prop, with college $(25+)$ & 0.0514 & 0.0316 & 0.0341 & 0.0242 \\
\hline & & 0.0891 & 0.0967 & 0.0966 & 0.0790 \\
\hline \multirow{12}{*}{$\mathbf{S}$} & prop. vacant & -0.0129 & -0.0159 & 0.0024 & -0.0253 \\
\hline & & 0.0699 & 0.1316 & 0.0961 & 0.1150 \\
\hline & median year built & 3.7454 & 1.6768 & 9.7692 & 3.8086 \\
\hline & & 31.656 & 9.388 & 97.050 & 19.652 \\
\hline & prop. smaller structures (<4 units) & 0.0044 & 0.0318 & 0.0169 & 0.0144 \\
\hline & & 0.1076 & 0.1479 & 0.1202 & 0.1249 \\
\hline & Avg. Rooms & 0.0641 & 0.0401 & 0.0638 & 0.0789 \\
\hline & & 0.5041 & 0.7512 & 0.5514 & 0.6116 \\
\hline & Avg. Bedrooms & 0.0097 & -0.0025 & 0.0091 & -0.0129 \\
\hline & & 0.2725 & 0.4432 & 0.3058 & 0.3513 \\
\hline & Prop. housing built in 10 years ${ }^{\circ}$ & 0.1434 & 0.0546 & 0.0555 & 0.0569 \\
\hline & & 0.1877 & 0.0942 & 0.0949 & 0.0949 \\
\hline \multirow{8}{*}{$M$} & Place: log of Housholds & 0.1408 & 0.0007 & 0.0335 & 0.1361 \\
\hline & & 0.1539 & 0.0624 & 0.1004 & 0.0368 \\
\hline & Place: log of Median Home Value & 0.3784 & 0.4272 & 0.3506 & 0.2807 \\
\hline & & 0.2072 & 0.3419 & 0.1242 & 0.0815 \\
\hline & Place: log of Median Rent & 0.0836 & 0.0632 & 0.0599 & 0.0444 \\
\hline & & 0.1200 & 0.1113 & 0.0894 & 0.0858 \\
\hline & Place: log of median income & 0.2829 & 0.2799 & 0.2633 & 0.2693 \\
\hline & & 0.0895 & 0.1236 & 0.0583 & 0.0479 \\
\hline
\end{tabular}




\begin{tabular}{|c|c|c|c|c|}
\hline Place: prop. w/children & -0.0069 & 0.0088 & -0.0086 & -0.0080 \\
\hline & 0.0285 & 0.0197 & 0.0337 & 0.0145 \\
\hline Place: prop. families w/children & -0.0203 & 0.0028 & -0.0206 & -0.0246 \\
\hline & 0.0278 & 0.0155 & 0.0312 & 0.0143 \\
\hline District: log expend per pupil. & 0.5007 & 0.5270 & 0.4594 & 0.5221 \\
\hline & 0.2093 & 0.0873 & 0.1805 & 0.2034 \\
\hline No. Obs (all variables) ${ }^{\mathrm{C}}$ & 109,905 & 749 & 846 & 608 \\
\hline
\end{tabular}

Note: Mean and standard deviation (reported below the mean) of variable changes, 1990-2000.

a. Numbers for "average" values of the Zone variables are counts of block groups for which the specified variables are equal to one. All other variables are means, with standard deviations in smaller print below.

b. Average is reported in levels, not differences. This variable is also entered into the regressions in levels.

c. The Number of Observations row represents the minimum number of observations across all variables. 
Table 2: OLS estimates.

\begin{tabular}{|c|c|c|c|c|c|c|c|c|}
\hline & \multicolumn{2}{|c|}{2.1} & \multicolumn{2}{|l|}{2.2} & \multicolumn{2}{|c|}{2.3} & \multicolumn{2}{|l|}{2.4} \\
\hline & Coef. & se & Coef. & se & Coef. & se & Coef. & se \\
\hline EZ Round 1 & 0.2211 *** & 0.0254 & $0.2211^{* * *}$ & 0.0260 & $0.4020 * \star \star$ & 0.0433 & 0.4272 *** & 0.0435 \\
\hline EZ Round 2 & 0.0391 * & 0.0205 & 0.0276 & 0.0211 & & & & \\
\hline EZ ever & -0.0218 & 0.0149 & -0.0050 & 0.0155 & & & & \\
\hline Working Families & -0.0056 & 0.0141 & & & -0.0100 & 0.0137 & & \\
\hline Poverty (150\%) & -0.0229 & 0.0132 & & & $-0.0279 * \star$ & 0.0131 & & \\
\hline $\log ($ med. Inc) & 0.1294 *** & 0.0069 & & & $0.1283 * * *$ & 0.0068 & & \\
\hline White & $0.1502 * \star \star$ & 0.0085 & & & $0.1401 * * \star$ & 0.0085 & & \\
\hline Commute & -0.0004 * & 0.0002 & & & $-0.0005^{\star \star}$ & 0.0002 & & \\
\hline Pop. Density & $1.59 \times 10^{-06} \star \star$ & $7.65 \times 10^{-07}$ & & & $2.17 \times 10^{-06} \star \star$ & $8.94 \times 10^{-07}$ & & \\
\hline Industrial Employment & -0.0191 & 0.0117 & & & -0.0131 & 0.0116 & & \\
\hline Renters & 0.0134 & 0.0169 & & & 0.0032 & 0.0168 & & \\
\hline Long Term Resident & -0.1368 *** & 0.0075 & & & 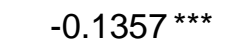 & 0.0075 & & \\
\hline Families with Children & -0.0088 & 0.0169 & & & -0.0073 & 0.0170 & & \\
\hline College & $0.3053^{* * *}$ & 0.0130 & & & $0.3086 * \star \star$ & 0.0129 & & \\
\hline Vacancy Rate & -0.0238 & 0.0196 & & & -0.0163 & 0.0192 & & \\
\hline med. Year Built & $0.0014 * \star \star$ & 0.0001 & & & 0.0014 *** & 0.0001 & & \\
\hline Small Structures & -0.1070 *** & 0.0160 & & & -0.1141 *** & 0.0159 & & \\
\hline Avg. Rooms & $0.0937^{* * *}$ & 0.0036 & & & $0.0955^{* \star *}$ & 0.0036 & & \\
\hline Avg. Bedrooms & $-0.0245^{* * *}$ & 0.0069 & & & $-0.0275^{\star \star \star}$ & 0.0069 & & \\
\hline Construction & $0.0600 * \star \star$ & 0.0065 & & & $0.0651 * * *$ & 0.0067 & & \\
\hline Place Households & $-0.1162 * * *$ & 0.0076 & $-0.0516 * \star \star$ & 0.0080 & $-0.1090 * \star \star$ & 0.0076 & $-0.0427^{\star \star *}$ & 0.0080 \\
\hline Place log median Value & $0.5379 * \star \star$ & 0.0121 & 0.5671 *** & 0.0124 & $0.5301 * \star \star$ & 0.0123 & $0.5597^{\star \star \star}$ & 0.0125 \\
\hline Place log median Rent & $0.0968 * \star *$ & 0.0083 & 0.1332 *** & 0.0093 & $0.1074 * \star \star$ & 0.0084 & $0.1434 * \star \star$ & 0.0094 \\
\hline Place log median income & -0.0021 & 0.0153 & 0.1350 *** & 0.0162 & -0.0048 & 0.0152 & $0.1304 * * *$ & 0.0160 \\
\hline Place families with children & $-0.3902^{* * *}$ & 0.0716 & $-0.8698 * * *$ & 0.0750 & $-0.3537^{\star \star \star}$ & 0.0664 & $-0.8027^{\star \star \star}$ & 0.0686 \\
\hline Place traditional families & 0.3963 *** & 0.0725 & $0.8986 * \star \star$ & 0.0786 & $0.3366 * \star \star$ & 0.0669 & 0.8222 *** & 0.0720 \\
\hline Place expenditure/Pupil & 0.0053 & 0.0043 & 0.0103 ** & 0.0045 & 0.0062 & 0.0043 & $0.0122 * * \star$ & 0.0046 \\
\hline Observations & 106,2 & & 106,9 & & 104,8 & 327 & 104,849 & \\
\hline r-squared & 0.187 & & 0.08 & & 0.188 & & 0.0852 & \\
\hline
\end{tabular}

Note: All models also include MSA fixed effects, county-level natural amenity score and MSA-specific rent gradients . ${ }^{* * *},{ }^{* * *}{ }^{*}$ for $\mathrm{p}<0.01,<0.05,<0.10$, respectively 
Table 3: Three stage least squares models: Price equation and EZ Round 1 coefficients from non-price equations.

\begin{tabular}{|c|c|c|c|c|c|c|c|c|}
\hline & \multicolumn{4}{|c|}{3.1} & \multicolumn{4}{|c|}{3.2} \\
\hline & \multicolumn{2}{|c|}{ Price equation } & \multicolumn{2}{|c|}{ Non-price equations } & \multicolumn{2}{|c|}{ Price equation } & \multicolumn{2}{|c|}{ Non-price equations } \\
\hline & Coef. & se & EZ1 Coef. & se & Coef. & se & EZ1 Coef. & se \\
\hline EZ Round 1 & $0.3458 * \star \star$ & 0.0296 & & & $0.4895^{\star \star *}$ & 0.0399 & & \\
\hline EZ Round 2 & $0.2883 * \star \star$ & 0.0360 & & & & & & \\
\hline EZ ever & 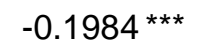 & 0.0251 & & & & & & \\
\hline lagged Housing values & 0.1454 *** & 0.0309 & & & $0.0705^{* *}$ & 0.0313 & & \\
\hline Working Families & $-1.0078^{* \star *}$ & 0.2920 & $0.0439 * * *$ & 0.0073 & -0.8917 *** & 0.2946 & $0.1095 * \star *$ & 0.0102 \\
\hline Poverty (150\%) & $-1.2709 * \star \star$ & 0.2204 & $0.0259 * * *$ & 0.0059 & -3.0086 *** & 0.2180 & $0.0742 * * *$ & 0.0089 \\
\hline $\log ($ med. Inc) & $0.9833 * \star *$ & 0.2096 & 0.0042 & 0.0132 & 0.2725 & 0.2123 & $0.0500 * \star$ & 0.0199 \\
\hline White & $-1.3906 * \star \star$ & 0.0586 & $0.0804 * * *$ & 0.0119 & $-1.4209 * \star \star$ & 0.0582 & $0.2182 * * *$ & 0.0176 \\
\hline Commute & $-0.0315^{\star \star *}$ & 0.0054 & 0.2040 & 0.3472 & $-0.0538^{\star \star *}$ & 0.0054 & 1.0212 ** & 0.5139 \\
\hline Pop. Density & 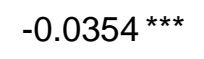 & 0.0067 & $-0.5590 * * *$ & 0.1392 & 0.0816 *** & 0.0081 & $-2.1289 * \star \star$ & 0.1728 \\
\hline Industrial Employment & $-1.3176^{\star \star \star}$ & 0.1150 & -0.0073 & 0.0072 & $-0.2592^{\star \star}$ & 0.1208 & $-0.1580^{* * *}$ & 0.0101 \\
\hline Renters & $3.1169 * \star \star$ & 0.4363 & $-0.0237^{\star * \star}$ & 0.0061 & $1.6915^{\star \star \star}$ & 0.4640 & 0.0013 & 0.0092 \\
\hline Long Term Resident & $0.3351 *$ & 0.1739 & 0.0060 & 0.0095 & 0.2010 & 0.1725 & $0.1052^{* * *}$ & 0.0140 \\
\hline Families with Children & $1.3279 * \star \star$ & 0.4503 & $0.0239 * * \star$ & 0.0044 & -0.6417 & 0.4575 & $0.1113^{* * *}$ & 0.0064 \\
\hline College & $1.9797 * \star \star$ & 0.0936 & $-0.0257^{\star \star \star}$ & 0.0076 & $1.4849 * \star \star$ & 0.0928 & $0.0245 * *$ & 0.0115 \\
\hline Vacancy Rate & $-0.7783^{* \star \star}$ & 0.1964 & $0.0128 * * *$ & 0.0048 & -0.2926 & 0.1936 & 0.0089 & 0.0073 \\
\hline med. Year Built & -0.0081 *** & 0.0015 & $-1.5928 * *$ & 0.7915 & $-0.0035^{\star *}$ & 0.0015 & $-10.1993^{* * *}$ & 1.1945 \\
\hline Small Structures & $4.3845^{\star \star \star *}$ & 0.4260 & -0.0069 & 0.0057 & $2.3475^{\star \star *}$ & 0.4776 & 0.0606 *** & 0.0083 \\
\hline Avg. Rooms & $0.9838 * \star \star$ & 0.0545 & $-0.0626 * \star \star$ & 0.0227 & $1.3029 * \star \star$ & 0.0560 & $-0.1620 * \star \star$ & 0.0326 \\
\hline Avg. Bedrooms & $-4.0112^{\star \star \star}$ & 0.3170 & $0.0273 * \star$ & 0.0108 & $-3.9269 \star \star \star$ & 0.3479 & $-0.0581 * \star \star$ & 0.0159 \\
\hline Construction & $1.1707 * \star \star$ & 0.1242 & $0.0485 * \star \star$ & 0.0120 & 0.3183 ** & 0.1357 & $0.3520 * \star \star$ & 0.0174 \\
\hline Place Households & -0.1818 *** & 0.0228 & & & -0.0056 & 0.0232 & & \\
\hline Place log median Value & $0.6433 * \star \star$ & 0.0191 & & & $0.6014 * \star \star$ & 0.0193 & & \\
\hline Place log median Rent & -0.0134 & 0.0173 & & & 0.0064 & 0.0168 & & \\
\hline Place log median income & -0.2226 *** & 0.0431 & & & $-0.1897 \star \star \star$ & 0.0409 & & \\
\hline Place families with children & $-0.7608 * \star \star$ & 0.2318 & & & 0.1073 & 0.2305 & & \\
\hline Place traditional families & -0.0178 & 0.1763 & & & -0.1916 & 0.1721 & & \\
\hline Place expenditure/Pupil & $0.0157 * \star$ & 0.0074 & & & $0.0146 * \star$ & 0.0071 & & \\
\hline observations & 105,332 & & & & 104,827 & & & \\
\hline
\end{tabular}

Note: All models include MSA fixed effects; $P$ equation also includes city-specific rent gradients and a county-level natural amenity score. ${ }^{* * *},{ }^{* * *},{ }^{*}$ for $\mathrm{p}<0.01,<0.05,<0.10$, respectively. 
Table 4: OLS and 2SLS estimates with spill-overs

\begin{tabular}{|c|c|c|c|c|c|c|}
\hline & \multirow{2}{*}{\multicolumn{2}{|c|}{$\begin{array}{c}\text { Column } 4.1 \\
\text { Price equation }\end{array}$}} & \multicolumn{4}{|c|}{ Column 4.2} \\
\hline & & & \multicolumn{2}{|c|}{ Price equation } & \multicolumn{2}{|c|}{ Non-price equations } \\
\hline & Coef. & se & Coef. & se & EZ1 Coef. & se \\
\hline EZ Round 1 & $0.2307^{* \star *}$ & 0.0255 & $0.3922 * \star \star$ & 0.0292 & & \\
\hline EZ Round 2 & 0.0450 ** & 0.0207 & $0.3055^{\star \star \star}$ & 0.0387 & & \\
\hline EZ ever & -0.0242 & 0.0152 & $-0.2235^{\star * \star}$ & 0.0274 & & \\
\hline EZ Round 1 buffer & $0.1510 * \star \star$ & 0.0226 & 0.1853 *** & 0.0283 & & \\
\hline EZ Round 2 buffer & 0.0255 & 0.0202 & $0.0996 * * *$ & 0.0352 & & \\
\hline EZ ever buffer & -0.0150 & 0.0153 & $-0.1379 * * *$ & 0.0274 & & \\
\hline lagged Housing values & & & $0.1113 * * *$ & 0.0299 & & \\
\hline Working Families & -0.0099 & 0.0141 & $-0.8598 * * *$ & 0.2990 & $0.0462 * \star \star$ & 0.0074 \\
\hline Poverty (150\%) & -0.0238 * & 0.0132 & -1.7478 *** & 0.2158 & $0.0307^{\star \star \star}$ & 0.0060 \\
\hline $\log ($ med. Inc) & 0.1286 *** & 0.0069 & 0.7221 *** & 0.2254 & 0.0115 & 0.0134 \\
\hline White & $0.1467^{* \star *}$ & 0.0085 & -1.3487 *** & 0.0546 & $0.0926 * * *$ & 0.0120 \\
\hline Commute & -0.0004 * & 0.0002 & $-0.0372^{* * *}$ & 0.0052 & 0.2521 & 0.3540 \\
\hline Pop. Density & $1.53 \times 10^{-06} \star \star$ & $7.65 \times 10^{-07}$ & -0.0028 & 0.0063 & $-0.6950 * \star \star$ & 0.1416 \\
\hline Industrial Employment & -0.0179 & 0.0117 & -0.9502 *** & 0.1079 & -0.0113 & 0.0074 \\
\hline Renters & 0.0128 & 0.0169 & $2.2092^{* \star *}$ & 0.4765 & $-0.2365 * \star \star$ & 0.0546 \\
\hline Long Term Resident & $-0.1370 * * \star$ & 0.0075 & 0.2420 & 0.1770 & 0.0158 & 0.0097 \\
\hline Families with Children & -0.0080 & 0.0169 & 0.4846 & 0.4689 & 0.0303 *** & 0.0045 \\
\hline College & 0.3098 *** & 0.0131 & 1.7322 *** & 0.0877 & 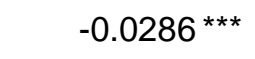 & 0.0078 \\
\hline Vacancy Rate & -0.0237 & 0.0196 & -0.6882 *** & 0.1858 & $0.0139 * * *$ & 0.0049 \\
\hline med. Year Built & 0.0014 *** & 0.0001 & $-0.0059 * * *$ & 0.0016 & -2.3788 *** & 0.8037 \\
\hline Small structures & -0.1104 *** & 0.0160 & $3.4074 * * *$ & 0.4735 & -0.0003 & 0.0058 \\
\hline Avg. Rooms & $0.0941 * * *$ & 0.0036 & $1.0959 * * *$ & 0.0530 & -0.0721 *** & 0.0230 \\
\hline Avg. Bedrooms & $-0.0235^{\star \star \star *}$ & 0.0070 & -3.9626 *** & 0.3450 & $0.0200 *$ & 0.0111 \\
\hline Construction & $0.0596 * \star \star$ & 0.0065 & $0.8130 * * \star$ & 0.1383 & $0.0701 * * *$ & 0.0124 \\
\hline observations & 106,209 & & 105,332 & & & \\
\hline
\end{tabular}

Note: All models include MSA fixed effects; $P$ equation also includes city-specific rent gradients and a county-level natural amenity score. All equations include the $M$ vector. ${ }^{* * *},{ }^{* *},{ }^{*}$ for $\mathrm{p}<0.01,<0.05,<0.10$, respectively. 
Table 5: Partial, Full and Indirect Effects, various models

\begin{tabular}{|lc|cccc|}
\hline Model & column(s) & Direct & Full & Indirect & Indirect/se(direct) \\
\hline OLS, control group identification & $2.1,2.2$ & 0.2211 & 0.2211 & 0.0000 & 0.00 \\
OLS, auxiliary regression & $2.3,2.4$ & 0.4059 & 0.4315 & 0.0256 & 0.59 \\
OLS, control group w/ buffers & $4.1^{a}$ & 0.2307 & 0.2310 & 0.0003 & 0.01 \\
2SLS, control group identification & 3.1 & 0.3458 & 0.3241 & -0.0218 & -0.74 \\
2SLS, auxiliary regression & 3.2 & 0.4802 & 0.4096 & -0.0705 & -1.73 \\
2SLS, control group w/ buffers & 4.2 & 0.3922 & 0.1013 & -0.2908 & -9.96 \\
\hline
\end{tabular}

${ }^{a}$ Full effect computed with results from an unreported regression which is available from the authors. 